\title{
Variations in Human Urinary O-Hydroxylysyl Glycoside Levels and Their Relationship to Collagen Metabolism
}

\author{
Jere P. Segrest and Leon W. Cunningham \\ From The Department of Biochemistry, Vanderbilt University School of Medicine, \\ Nashville, Tennessee 37203
}

A B S T R A C T Two O-hydroxylysyl glycosides, HylGal-Glc and Hyl-Gal, have been isolated from normal human urine and shown to be identical to two glycosides isolated from alkaline hydrolysates of collagen. A relatively sample and reproducible analytical procedure has been devised to measure the levels of these glycosides in human urine. By the use of this procedure it was shown that a normal diet has only a small effect on 24-hr urinary excretion levels of these glycosides indicating an endogenous origin. Urinary glycoside levels appear to be highest in children, roughly paralleling collagen turnover as indicated by urinary hydroxyproline levels. Collagen turnover equivalents calculated from urinary hydroxylysyl glycoside levels were found to be significantly larger than collagen turnover equivalents calculated from urinary hydroxyproline levels. This suggests that urinary glycosides are more quantitative indicators of collagen metabolism than urinary hydroxyproline.

The ratio of Hyl-Gal-Glc to Hyl-Gal was measured in urines of diseased as well as normal individuals and a bimodal distribution was found. Alkaline hydrolysates of different human connective tissue collagens showed that only bone collagen, of the collagens examined, had a low ratio of Hyl-Gal-Glc to Hyl-Gal compared to human urine. Other collagens examined had higher ratios than found in human urine. On the basis of these re-

A preliminary report of a portion of this work has appeared in J. Biol. Chem. (9).

Dr. Segrest was a Predoctoral Fellow of the Life Insurance Medical Research Fund and a U. S. Public Health Service Postdoctoral Fellow of the National Institute of General Medical Sciences during these investigations and presently is a resident in the Department of Pathology, Vanderbilt University School of Medicine, supported by Public Health Service Training Grant \#5T01GM 00290-09. This work was done in partial fulfillment of the requirements for the degree of Doctor of Philosophy, Vanderbilt University Graduate School, Nashville, Tenn. 37203.

Received for publication 2 January 1970 and in revised form 20 February 1970. sults it is postulated that the bimodal distribution of glycoside ratios represents two populations of collagen turnover, the lower ratio population having a high bone collagen turnover relative to the second population. Examination of the types of subjects making up the two populations supports this hypothesis. These data suggest that urinary O-hydroxylysyl glycoside excretion, in addition to providing a more quantitative estimate of collagen turnover than urinary hydroxyproline, may prove to be of value as a specific means of studying the metabolism of bone collagen.

\section{INTRODUCTION}

The urinary excretion of hydroxyproline peptides is a commonly used standard for the evaluation of collagen metabolism (1). Elevated levels of excretion over normal have been observed in hyperthyroidism (2), acromegaly (3), burned patients (4), and patients with bone-destroying lesions such as Paget's disease of bone (3), rickets of vitamin D-deficiency (5), metastatic carcinoma (6), and extensive fractures (7). There has been general agreement that in each of these disorders elevated urinary hydroxyproline excretion is a reflection of an abnormally high rate of collagen metabolism.

There are, however, at least two limitations to the use of urinary hydroxyproline peptide excretion as a measure of collagen metabolism. It has been estimated that less than $15 \%$ of the hydroxyproline of degraded collagen appears in the urine (8) so that urinary hydroxyproline peptides are poor indicators of total collagen turnover. The nonspecific nature of hydroxyproline as a marker is a second limitation. Hydroxyproline peptide excretion per se can give little information about metabolism of specfic regions of the tropocollagen molecule nor can it directly provide an estimation of the rate of collagen breakdown in particular tissues (e.g. bone vs. soft tissues). 
In a previous communication (9) we described the isolation and identification of the glycosides, Hyl-GalGlc and Hyl-Gal, from normal human urine. In each glycoside carbon 1 of galactose is attached to the $\delta$-hydroxyl group of hydroxylysine. Identical compounds were shown in the same communication to be present in alkaline hydrolysates of soluble guinea pig skin collagen. Similar compounds subsequently have been reported in bovine glomerular basement membrane (10) and in other collagens (11) and are apparently unique to collagen-like proteins, at least in higher animals such as mammals.

The present communication presents a description of the isolation and characterization of the urinary O-hydroxylysyl glycosides (OHLG), describes investigations of the relationship of these compounds to collagen metabolism, and compares their excretion with the urinary excretion of hydroxyproline peptides.

\section{METHODS}

Acetone precipitation of urine. Normal adult urine was used in the initial isolation and characterization experiments. 24-hr samples of urine were collected under $20 \mathrm{cc}$ of toluene and stored frozen at $-10^{\circ} \mathrm{C}$ until used. After thawing, the toluene was decanted and the urine filtered to remove sediment. The subsequent fractionation procedure is a modification of that reported by Estes and Golaszewski (12). 4 volumes of acetone were added and the solution was allowed to stand at $4^{\circ} \mathrm{C}$ overnight. The precipitate was then collected, washed once with cold acetone, and air dried. It was then dissolved in a minimal quantity of distilled water, 5-10 $\mathrm{ml} \mathrm{g}^{-1}$, and the $\mathrm{pH}$ was simultaneously adjusted to 9.5 . This procedure was then repeated twice more for a total of three acetone precipitations. A final yield of 8-10 $\mathrm{g}$ of dried precipitate was obtained from a $24 \mathrm{hr}$ collection of normal urine.

Gel filtration of the acetone precipitate. The dried precipitate, up to $10 \mathrm{~g}$, was dissolved in no more than $50 \mathrm{ml}$ of $0.1 \mathrm{M}$ pyridine acetate buffer, $\mathrm{pH} 5.0$, and subjected to gel filtration on a $2000 \mathrm{ml}$ column of Sephadex G-25 (Pharmacia Fine Chemicals, New Market, N. J.) which had been equilibrated with the same buffer. The temperature was approximately $25^{\circ} \mathrm{C}$. $20-\mathrm{ml}$ fractions were collected and analyzed for ninhydrin-positive material by the method of Moore and Stein (13), adapted for the AutoAnalyzer as described by Technicon Chromatography Corp. Tarrytown, N. Y., and for carbohydrate by the automated orcinol procedure developed in this laboratory (14).

Column chromatography of glycopeptide fractions on Dowex 50. Glycopeptide fractions obtained from acetone precipitates of human urine were subjected to column chromatography on a $159 \times 0.9 \mathrm{~cm}$ column of Dowex 50 (Technicon Chromo beads, Type A, lot $129 \mathrm{~A}, \mathrm{X}-12$ ) maintained at $55^{\circ} \mathrm{C}$. Elution was begun with $0.2 \mathrm{~N}$ sodium citrate buffer, $\mathrm{pH} 3.25$, with a change to $\mathrm{pH} 4.25,0.2 \mathrm{~N}$ sodium citrate buffer at $340 \mathrm{ml}$. The flow rate was $60 \mathrm{ml} / \mathrm{hr}$ and 4-ml fractions were collected.

Sephadex $G-10$ desalting of glycopeptide fractions. Glycopeptide fractions, up to $10 \mathrm{ml}$ in total volume, were subjected to gel filtration on a $1000 \mathrm{ml}$ column of Sephadex G-10 (Pharmacia) equilibrated with $0.1 \mathrm{M}$ pyridine acetate buffer, $\mathrm{pH}$ 5.0. By this procedure, glycopeptide fractions were found to be easily separated from citrate.

Amino acid and hexose analyses. Aliquots of desalted glycopeptide fractions were hydrolyzed for $20 \mathrm{hr}$ at $110^{\circ} \mathrm{C}$ in $6 \mathrm{~N} \mathrm{HCl}$. Quantitative amino acid analyses (15) were performed with a model 120 Beckman-Spinco automatic amino acid analyzer (Beckman Instruments, Inc., Spinco Division, Palo Alto, Calif.). Quantitative hexose analyses were performed on these same samples by the orcinol procedure (13).

Identification of hexoses. For identification of hexoses glycopeptide fractions were hydrolyzed in $2 \mathrm{~N} \mathrm{HCl}$ for $2 \mathrm{hr}$ at $110^{\circ} \mathrm{C}$. Descending chromatography was carried out in 1-butanol-pyridine-water $(6: 4: 3)$. Chromatograms were sprayed with aniline-phthalate for detection of hexoses (16).

Quantitative hexose analyses. Glucose and galactose were measured in aliquots of glycopeptide fractions by glucose and galactose oxidase as described previously (17).

Paper electrophoresis and chromatography. Electrophoresis of glycopeptide fractions was performed with a Savant high voltage flat plate apparatus for $1 \mathrm{hr}$ at $2000 \mathrm{v}$ in $\mathrm{pH}$ 3.45 pyridine acetate buffer.

Descending paper chromatography of glycopeptide fractions was carried out in propanol-water-ammonia $(60: 40: 1)$.

Screening procedure for measuring urinary $O$-hydroxylysyl glycoside levels. 24-hr samples of urine, total volumes corrected by comparing expected with actual creatinine levels (18), were collected under toluene as described. $100-\mathrm{ml}$ aliquots were taken from each sample and evaporated on a rotary evaporator to as small a volume as possible, generally between 30 and $50 \mathrm{ml}$, without precipitation of urinary solutes. $6 \mathrm{ml}$ of each condensate were then desalted over a $225 \mathrm{ml}$ column of Sephadex G-10 (Pharmacia) equilibrated and eluted with $0.1 \mathrm{~m}$ pyridine acetate buffer, $\mathrm{pH}$ 5.0. The desalted fraction was lyophilized and an aliquot subjected to column chromatography on a $21 \times 0.9 \mathrm{~cm}$ column of Dowex 50, (Spinco ion exchange resin, type $15 \mathrm{~A}, \mathrm{X}-8$ ) maintained at $55^{\circ} \mathrm{C}$. The initial buffer was $0.24 \mathrm{~N}$ sodium acetate, $\mathrm{pH} 3.25$, with a change to a $\mathrm{pH} 4.25,0.2 \mathrm{~N}$ sodium acetate, at $60 \mathrm{ml}$. The flow rate was $60 \mathrm{ml} / \mathrm{hr}$. $1-\mathrm{ml}$ fractions were collected.

Dietary experiments. The effects of diet on the excretion of urinary OHLG's were investigated by placing two healthy adult males on gelatin and collagen-free diets for 1 and 2 wk. The diet (19) consisted of varying proportions of milk, cheese, eggs, vegetables, bread, butter, and juices. All meat, fish, jello, soft candy, or ice cream was omitted. Several 24-hr samples of urine were collected from each individual. Volunteer $\mathrm{A}$, at the cessation of the low gelatin diet, was given $24 \mathrm{~g}$ of commercial gelatin (Gelateins, Inc., Atlanta, Ga.) and a $24 \mathrm{hr}$ urine sample was collected.

Alkaline hydrolysis of commercial gelatin and human collagen preparations. Gelatin $(0.5 \mathrm{~g})$ and collagen $(100 \mathrm{mg})$ were hydrolyzed in $6 \mathrm{ml}$ of $3 \mathrm{~N} \mathrm{NaOH}$ for $16 \mathrm{hr}$ at $90^{\circ} \mathrm{C}$ in Vycor test tubes (Corning Glass Works, Corning N. Y.). The insoluble material was removed by centrifugation at $15,000 \mathrm{rpm}$ for $15 \mathrm{~min}$. Each hydrolysate was then desalted on a $225 \mathrm{ml}$ column of Sephadex G-10. An aliquot of the desalted, lyophilized fraction was analyzed for OHLG content by column chromatography on a $21 \times 0.9 \mathrm{~cm}$ Dowex 50 column, $\mathrm{X}-8$, as described.

Determination of the effects of age and disease on the $24 \mathrm{hr}$ excretion of urinary O-hydroxylysyl glycosides. 24-hr urine samples were collected from a male and a female in the following age brackets: $2,7,13,25,40$, and 70 $\mathrm{yr}$ of age. The samples were collected from both normal 
unhospitalized young adults and from patients about to be discharged from the hospital who were admitted for relatively minor surgical procedures such as eye surgery, for nonsurgical correction of such orthopedic problems as foot and hand malformations, and for relatively minor pediatric illnesses such as bronchiolitis and diarrhea.

24-hr urines from patients with heritable and nonheritable connective tissue disorders were collected. Samples were kindly provided by Dr. Victor A. McKusick of the Johns Hopkins University Department of Medicine from patients with the heritable connective tissue disorders of Ehlers-Danlos, the Marfan syndrome, osteogenesis imperfecta, pseudoxanthoma elasticum, and achondroplasia. Samples from individuals with the connective tissue disorders, myositis ossificans progressiva and pyknodysostosis, were collected from Vanderbilt Hospital patients, as were samples from nonheritable disorders related to connective tissue including "collagen-vascular" diseases of rheumatoid arthritis, systemic lupus erythematosus, and systemic scleroderma. Among the other nonheritable disorders were urines from a severely burned individual, a patient with active thyrotoxicosis (Grave's disease), and a child with cystic fibrosis.

$100-\mathrm{ml}$ aliquots of each sample were subjected to analysis for OHLG's.

Calculation of collagen equivalents from 24-hr excretion levels of hydroxylysyl glycosides and urinary hydroxyproline. By use of the factor 0.0045 (17), 24-hr collagen turnover equivalents (the minimal amount of collagen, in grams, catabolized in $24 \mathrm{hr}$ ), abbreviated CEG, have been calculated from the 24-hr excretion levels of urinary OHLG's. Although insoluble collagen has a higher hexose content than soluble collagen (20), most of the difference is due to a sialic acid containing glycopeptide present only in insoluble collagen. Thus, it is a reasonable assumption that the hexose contained in the OHLG's represents about $0.45 \%$ of the weight of insoluble as well as soluble collagen.

By use of the factor 0.122 , urinary levels of hydroxyproline per $24 \mathrm{hr}$ as reported by other investigators (21) have been converted to collagen turnover equivalents, abbreviated CEP, and the levels with age compared with collagen equivalents calculated from urinary OHLG's (CEG).

Determination of urinary hydroxyproline excretion. Nine 24-hr samples of urine, for which levels of OHLG's had been previously determined, were selected for the determination of urinary hydroxyproline. Five of the samples were from normal individuals of wide age range and four were urines from diseased individuals. Urinary hydroxyproline was measured by the method of Prockop and Udenfriend (22).

Preparation of insoluble collagens from human connective tissues. Human connective tissues for collagen preparation were obtained from autopsy material and amputations. All patients from whom samples were obtained were without known connective tissue diseases. Human skin was obtained at autopsy from the anterior abdomen of cadavers. Tendon was Achilles tendon from the amputated leg of an adult male removed because of vascular insufficiency. Adult cartilage collagen was joint cartilage from the same amputated leg. Infant joint cartilage was obtained from a full term infant (Anatomical Board). Samples of hard cortical bone came from amputational as well as from autopsy material. All tissues were stored at $-10^{\circ} \mathrm{C}$ until use. All extraction procedures were performed at $0-5^{\circ} \mathrm{C}$.

The fat, epidermis, and hair layers from human skin samples were scraped off. The cleaned skin was weighed, cut into small pieces, and ground to a fine mince with a tissue grinder before extraction.

Human Achilles tendon was cleaned of muscle and fat, washed with cold distilled water, weighed, and cut into small pieces for extraction.

Infant and adult epiphyseal cartilages were washed with distilled water, weighed, and cut into pieces as small as possible. Before preparation of insoluble collagen from the cartilages, they were decalcified with two changes of solution of cold $0.35 \mathrm{M}$ sodium EDTA (Fisher) at $\mathrm{pH} 8.1$ (10 $\mathrm{ml} / \mathrm{g}$ ).

Hard human cortical bone was carefully cleaned of all marrow elements and stripped of its periosteum. The bone was then crushed to smaller pieces by pounding with a mallet and dehydrated with cold acetone. After drying of the bone fragments with a nitrogen jet, the fragments were ground to a powder in a Waring Blendor containing liquid nitrogen. The powder was dried under nitrogen and weighed.

The bone powder was decalcified four times ( $24 \mathrm{hr}$ each) with cold $0.35 \mathrm{M}$ sodium EDTA, pH 8.1 (10 ml $/ \mathrm{g})$. After each extraction, the solution was centrifuged at $5000 \mathrm{rpm}$ at $4^{\circ} \mathrm{C}$ for $10 \mathrm{~min}$ and the supernatant was discarded. The EDTA was removed after the last extraction by four washings with cold distilled water.

Each tissue was then extracted four times $24 \mathrm{hr}$ each) with 10 volumes $(10 \mathrm{ml} / \mathrm{g})$ of $0.5 \mathrm{M}$ sodium acetate and the extract filtered through cheesecloth and discarded in order to remove soluble proteins and mucopolysaccharides. After washing three times with 10 volumes of water, the tissue was extracted three times with 10 volumes of $0.5 \mathrm{M}$ acetic acid and the supernatent discarded. The residue was again washed with water, dehydrated with acetone, and lipid material removed by treating with ether using a mortar and pestle. After further washing with acetone and then with water, the collagen was lyophilized and ground to a powder.

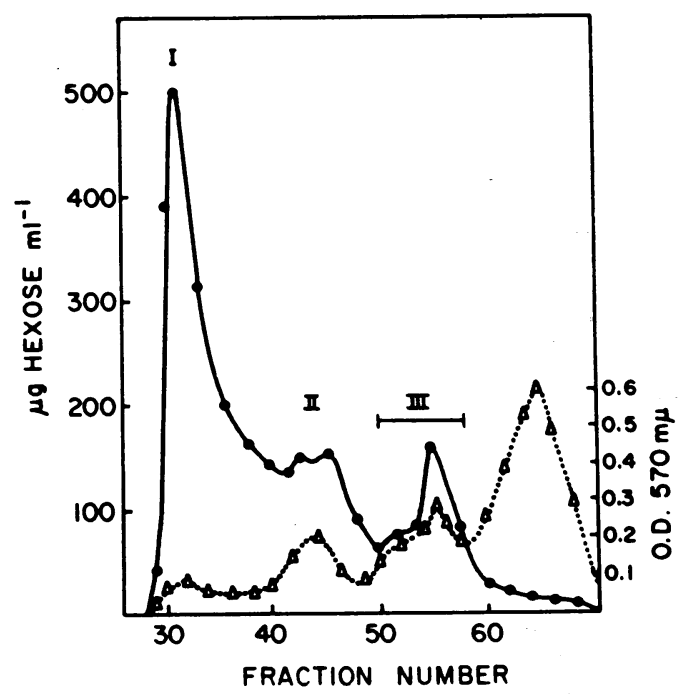

FIgure 1 Gel filtration on Sephadex G-25 of acetone precipitate from normal human urine. (-- $-\triangle--\triangle---)$ ninhydrin reaction, o.D. $570 \mathrm{~m} \mu$; ( action, $\mu \mathrm{g}$ hexose $\mathrm{ml}^{-1}$. 

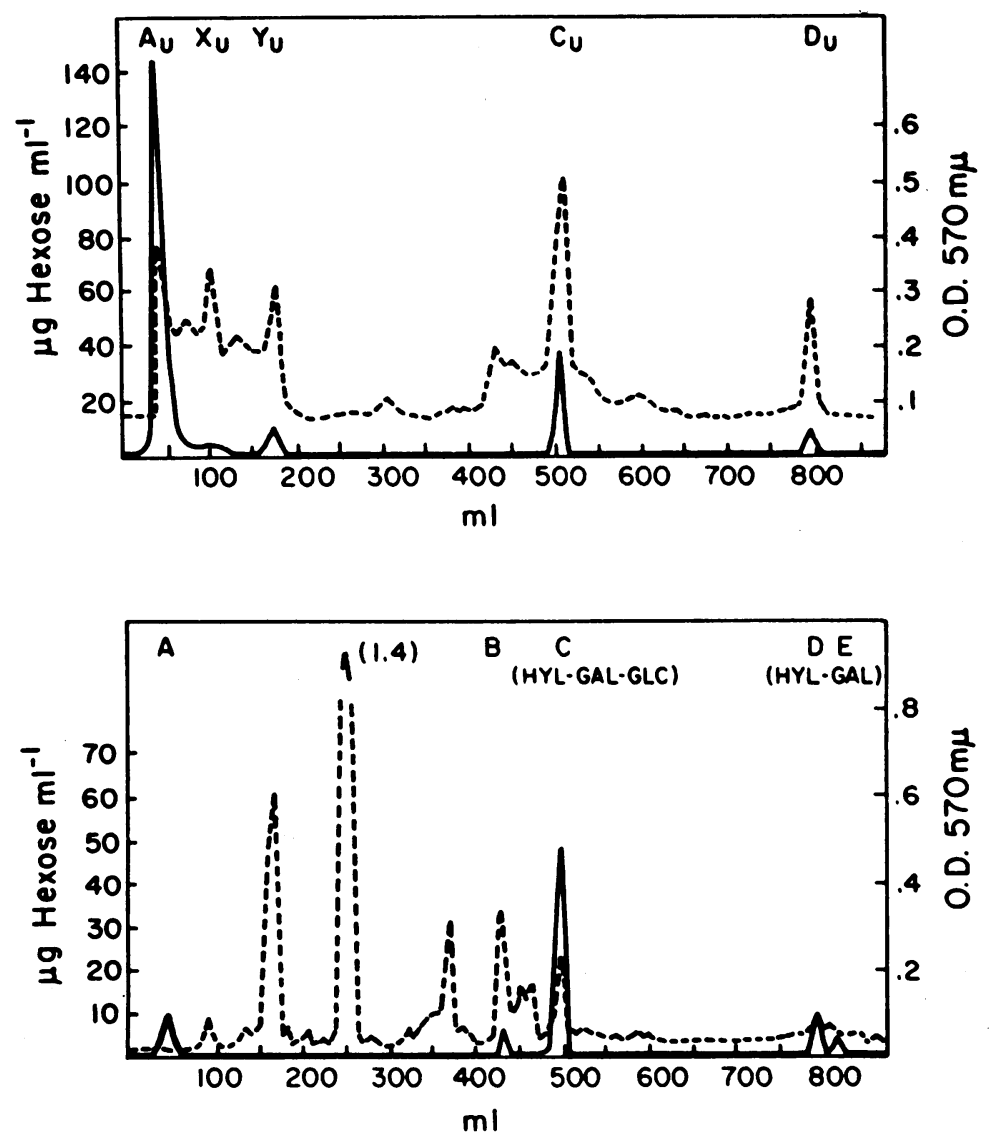

Figure 2 Column chromatography of hydroxylysyl glycosides on Dowex 50. (Upper) Sephadex G-25 pool III, a low molecular weight glycopeptide fraction from normal human urine; (- . . -) ninhydrin reaction, o.D $570 \mathrm{~m} \mu$; ( hydrolysate of the glycopeptide fraction from a collagenase digest of guinea pig skin collagen: (-.---) ninhydrin reaction, o.D. $570 \mathrm{~m} \mu$ $(\longrightarrow)$ orcinol reaction, $\mu \mathrm{g}$ hexose $\mathrm{ml}^{-1}$.

\section{RESULTS}

Isolation and partial characterization of human urinary O-hydroxylysyl glycosides

Gel filtration. The result of gel filtration on a 2000 $\mathrm{ml}$ column of Sephadex G-25 of the acetone precipitate obtained from normal human urine is shown in Fig. 1. At least three distinct carbohydrate-containing fractions may be distinguished. The three fractions are well separated from the majority of the ninhydrin positive material. Pool I contained no hydroxylysine and pool II only small quantities (less than $5 \%$ of pool III) on the basis of amino acid analysis after acid hydrolysis. However, by the same procedure, pool III contained appreciable quantities of hydroxylysine.

Dowex 50 column chromatography. Pool III, as indicated by the brackets, in addition to containing most of the hydroxylysine, contained approximately $16 \%$ of the total hexose and amounted to approximately $200 \mathrm{mg}$ of material per $24 \mathrm{hr}$ sample of urine. A typical elution pattern for the chromatography of 200 of pool III on a $159 \times 0.9 \mathrm{~cm}$ column of Dowex 50 is shown in Fig. 2 (upper). Fig. 2 (lower) shows the results of chromatography by the same procedure of an alkaline hydrolysate of soluble guinea pig skin collagen. Fractions $\mathrm{X}_{\mathbf{u}}$ and $\mathrm{Y}_{\mathbf{u}}$ have not been characterized but contain no hydroxylysine after acid hydrolysis. The breakthrough, fraction $A_{u}$, contains about $70 \%$ of the orcinol positive material and no hydroxylysine after acid hydrolysis. The elution volume of fractions $C_{u}$ and $D_{u}$ coincide exactly with that observed for the alkaline hydrolysate compounds Hyl-Gal-Glc and Hyl-Gal. Fractions $\mathrm{Cu}_{\mathrm{u}}$ and $\mathrm{D}_{\mathrm{u}}$, both of which contain hydroxylysine after acid hydrolysis, together represent $22 \%$ of the total hexose from G-25 pool III. 
Partial characterization of urinary fractions $C_{\mathrm{u}}$ and $D$ u. Hydroxylysine is the only amino acid present in urinary fractions $C_{u}$ and $D_{u}$ on the basis of amino acid analysis after acid hydrolysis (Table I). Chromatographic identification of hexoses and the results of Table I indicate that fractions $C_{u}$ and $D_{u}$ are identical, respectively, to Hyl-Gal-Glc and Hyl-Gal isolated from soluble collagen hydrolysates.

Fig. 3 (upper) shows the results of a comparison of the electrophoretic mobilities of the urinary and collagen hydrolysate OHLG's. This comparison, together with the results of paper chromatography illustrated in Fig. 3 (lower) confirms that urinary fraction $C_{a}$ is identical by all criteria utilized, to the glycoside, O-glucosyl-Ogalactosyl-hydroxylysine, isolated from alkaline hydrolysates of soluble guinea pig skin collagen and that urinary fraction $D_{u}$ is identical to the most rapidly eluting $\mathrm{O}$-galactosyl-hydroxylysine observed in collagen hydrolysates. The second Hyl-Gal component observed in very small amount in the collagen hydrolysates has been assumed to be derived by alkali catalyzed racemization of the hydroxylysine moiety and the presence of a single Hyl-Gal component in urine would seem to afford support for this interpretation.

The effects of diet, age, and disease on the excretion of urinary O-hydroxylysyl glycosides

Screening procedure. Before a number of urines could be effectively analyzed for changes in OHLG's under varying conditions of diet, age, and disease, it was necessary to devise a procedure of sufficient rapidity, reproducibility, and accuracy. Acetone precipitation recovers a maximum of only $65-75 \%$ of the OHLG's from a sample of urine and for this reason was felt to be unsuitable for use in concentrating these glycosides for analysis. Urinary concentration was achieved through partial evaporation followed by desalting on Sephadex G-10. In this way quantitative, concentrated, virtually salt-free aliquots of urinary OHLG's were obtained.

TABLE I

Composition of Hydroxylysyl Glycosides Isolated from Normal Human Urine

\begin{tabular}{|c|c|c|}
\hline Component & Peak C & Peak D \\
\hline & \multicolumn{2}{|c|}{ mole/mole hydroxylysine } \\
\hline Hydroxylysine* & 1.0 & 1.0 \\
\hline Hexose & $2.21 \pm 0.2$ & $1.33 \pm 0.1$ \\
\hline Galactose $\S$ & 0.70 & 0.82 \\
\hline Glucose $\|$ & 0.98 & 0.03 \\
\hline
\end{tabular}

* No other amino acids were present in quantities exceeding $0.05 \mathrm{~mole} / \mathrm{mole}$ of hydroxylysine.

$\ddagger$ Orcinol procedure, galactose standard (14).

\& Galactose oxidase (17).

\|Glucose oxidase (17).
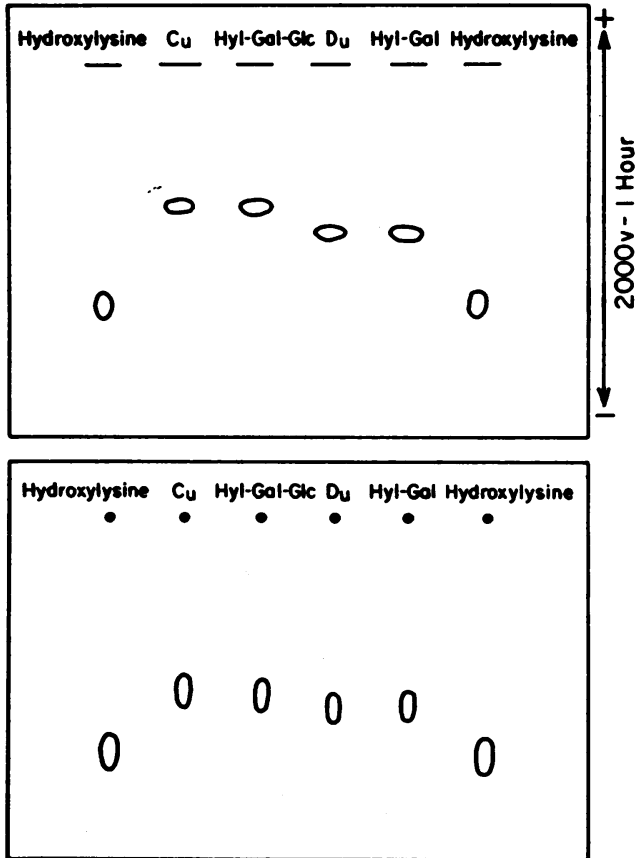

FIgURE 3 Paper electrophoresis and chromatography of hydroxylysyl glycosides. (Upper) Paper electrophoresis of Fractions $C_{u}$ and $D_{u}$ from acetone precipitate of normal human urine and Hyl-Gal-Glc and Hyl-Gal isolated from guinea pig skin alkaline hydrolysates. Hydroxylysine serves as the standard. Spots developed with ninhydrin. (Lower) Paper chromatography of Fractions $C_{u}$ and $D_{u}$ from acetone precipitate of normal human urine and Hyl-Gal-Glc and Hyl-Gal isolated from alkaline hydrolysates of guinea pig skin collagen. Buffer solution propanol: water: ammonia $(60: 40: 1)$. Hydroxylysine serves as the standard.

A Dowex 50 column was then used for analysis of urinary OHLG's. Fig. 4 (upper) shows the characteristic chromatographic pattern obtained for a concentrated, desalted aliquot of urine. Fig. 4 (lower) shows the elution positions of authentic Hyl-Gal-Glc and HylGal when rechromatographed under the same conditions as the aliquots of urine on the Dowex 50 column. The corresponding glycopeptide fractions are readily identified in the chromatogram of the urine as $C_{x}$ and $D_{x}$.

Fractions $C_{x}$ and $D_{x}$ from 10 normal urines chromatographed as in Fig. 4 were pooled. The resultant two samples were desalted on a $1000 \mathrm{ml}$ column of Sephadex G-10, lyophilized, and dissolved in $2 \mathrm{ml}$ of deionized water. There was a total of $152 \mu \mathrm{g}$ of hexose in the $C_{x}$ pool and $40 \mu \mathrm{g}$ of hexose in the $\mathrm{D}_{\mathbf{x}}$ pool by orcinol analysis.

Electrophoresis was performed on $0.05-\mathrm{ml}$ aliquots of the pooled samples of fractions $C_{x}$ and $D_{x}$. The major ninhydrin positive components in $C_{x}$ and $D_{x}$ had identical $R_{f}$ 's to the authentic compounds Hyl-Gal-Glc and Hyl$\mathrm{Gal}$, respectively, although in each case one or two other 


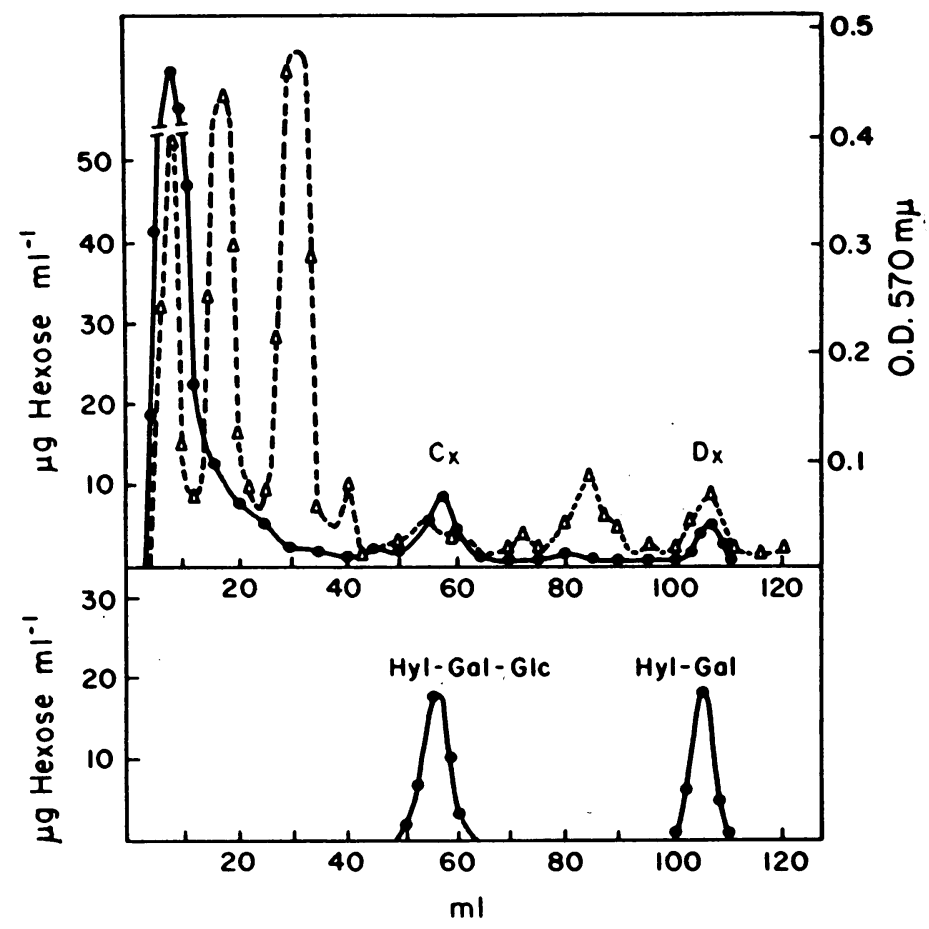

FIGURE 4 Dowex 50 column chromatography of concentrated human urine. (Upper) Concentrated, desalted normal human urine: $(--\triangle--\triangle---)$ ninhydrine reaction, o.D. $570 \mathrm{~m} \mu$; (-๑- - - ) orcinol reaction, $\mu \mathrm{g}$ hexose $\mathrm{ml}^{-1}$. (Lower) Purified compounds HylGal-Glc and Hyl-Gal from an acetone precipitate of normal human urine. (- - orcinol reaction, $\mu \mathrm{g}$ hexose $\mathrm{ml}^{-1}$.

minor ninhydrin spots were visible. No further purification was attempted as this experiment was intended only to confirm the identity of fractions $C_{\mathbf{x}}$ and $D_{\mathbf{x}}$.

Dowex 50 column chromatography was performed on combined $0.05-\mathrm{ml}$ aliquots of the pooled samples $C_{x}$ and Dx. Micromoles of each hydroxylysyl glycoside per milliliter were calculated from the total hexose per peak. Galactose standards were used. $C_{\mathbf{x}}$ was assumed to be the compound Hyl-Gal-Glc and $D_{x}$ to be Hyl-Gal. The results were then compared to a second estimate of micromoles of $C_{x}$ and $D_{x}$ per milliliter based upon each sample's concentration of hydroxylysine determined by amino acid analysis after acid hydrolysis. On the basis of these comparisons, it was shown that the measurement of Hyl-Gal-Glc and Hyl-Gal from Dowex 50 hexose peaks was a reasonably accurate and consistent procedure although the hexose based values were $25 \%$ higher than those based on hydroxylysine. Since hydroxylysine analysis is felt to be more specific and quantitative than hexose analysis, a factor of 0.8 has been used to correct calculations of urinary OHLG levels which are based on hexose analyses.

Effects of diet on 24-hr excretions of hydroxylysyl glycosides. Because of the unknown relationship of die- tary collagen to urinary levels of OHLG's, the effects of collagen-free and collagen-loading diets on urinary excretion of OHLG's were investigated before the effects of age and disease were assessed. Table II shows the results of these dietary experiments.

TABLE II

Effect of Diet on Urinary Hydroxylysyl Glycoside Excretion

\begin{tabular}{lcccc}
\hline \multicolumn{1}{c}{ Conditions } & Day & $\begin{array}{c}\text { Hyl-Gal- } \\
\text { Glc }\end{array}$ & Hyl-Gal & Total \\
\hline & & & $\mu$ moles $/ 24 \mathrm{hr}$ & \\
Volunteer A & & & & \\
Regular diet & 0 & 34.8 & 29.2 & 65.0 \\
Collagen-free diet & 2 & 25.9 & 22.1 & 48.0 \\
& 4 & 28.2 & 26.6 & 55.0 \\
& 5 & 32.0 & 26.2 & 58.2 \\
24 g of gelatin & - & 46.2 & 37.9 & 84.1 \\
Volunteer B & & & & \\
Regular diet & & & & \\
Collagen-free diet & 2 & 29.2 & 26.8 & 56.4 \\
& 5 & 21.6 & 19.2 & 40.8 \\
& 7 & 24.5 & 24.7 & 49.2 \\
& 15 & 29.7 & 29.7 & 59.4 \\
\hline
\end{tabular}


TABLE III

24-hr Excretion Levels* of O-Hydroxylysyl Glycosides in Normal and Diseased Urine

\begin{tabular}{|c|c|c|c|c|c|c|c|c|}
\hline \multirow[b]{2}{*}{$\begin{array}{l}\text { Subject } \\
\text { No. }\end{array}$} & \multirow[b]{2}{*}{ Age } & \multirow[b]{2}{*}{ Sex } & \multirow[b]{2}{*}{ Disorder } & \multicolumn{4}{|c|}{ Minimal $\mu$ moles of OHLG's } & \multirow{2}{*}{$\begin{array}{c}\text { Ratio of } \\
\text { Hyl-Gal-Glc } \\
\text { to Hyl-Gal }\end{array}$} \\
\hline & & & & $\begin{array}{l}\text { Hyl-Gal- } \\
\text { Glc }\end{array}$ & Hyl-Gal & Sum & per $m^{2}$ & \\
\hline $\mathrm{N} 1$ & 1 & $\mathrm{~F}$ & Normal & 14.3 & 18.3 & 32.6 & 65.5 & 0.78 \\
\hline $\mathrm{N} 2$ & 3 & $\mathbf{F}$ & Normal & 6.1 & 7.4 & 13.5 & 24.7 & 0.87 \\
\hline N3 & 5 & $F$ & Normal & 7.7 & 11.3 & 19.0 & 25.4 & 0.68 \\
\hline $\mathrm{N} 4$ & 7 & $\mathbf{M}$ & Normal & 20.6 & 18.2 & 38.8 & 45.4 & 1.13 \\
\hline N5 & 11 & $F$ & Normal & 23.0 & 39.1 & 62.1 & 46.1 & 0.59 \\
\hline N6 & 13 & $\mathbf{M}$ & Normal & 10.3 & 15.0 & 25.3 & 15.8 & 0.69 \\
\hline N7 & 17 & $\mathbf{M}$ & Normal & 23.4 & 21.8 & 45.2 & 20.4 & 1.07 \\
\hline N8 & 20 & $\mathbf{M}$ & Normal & 15.4 & 11.8 & 27.2 & 15.1 & 1.31 \\
\hline N9 & 24 & $\mathbf{M}$ & Normal & 23.4 & 20.6 & 44.0 & 18.3 & 1.14 \\
\hline N10 & 27 & $\mathbf{M}$ & Normal & 28.3 & 23.7 & 52.0 & 25.6 & 1.19 \\
\hline N11 & 28 & $\mathbf{M}$ & Normal & 33.2 & 27.8 & 61.0 & 22.5 & $1^{119}$ \\
\hline N12 & 44 & $\mathbf{M}$ & Normal & 18.4 & 14.3 & 32.7 & 15.6 & 1.29 \\
\hline N13 & 46 & $\mathrm{~F}$ & Normal & 15.2 & 11.8 & 27.0 & 15.6 & 1.29 \\
\hline N14 & 76 & $\mathrm{~F}$ & Normal & 20.1 & 16.9 & 37.0 & 21.7 & 1.19 \\
\hline N15 & 77 & $\mathbf{M}$ & Normal & 15.6 & 13.7 & 29.3 & 16.5 & 1.13 \\
\hline D1 & 17 & $F$ & Marfan & 17.1 & 17.0 & 34.1 & 24.3 & 1.00 \\
\hline D2 & 19 & $\mathrm{~F}$ & Marfan & 27.9 & 28.3 & 56.2 & 40.3 & 0.98 \\
\hline D3 & 19 & $\mathbf{M}$ & Marfan & 24.0 & 28.6 & 52.6 & 27.0 & 0.84 \\
\hline D4 & 40 & $\mathbf{M}$ & Marfan & 22.1 & 19.1 & 41.2 & 23.6 & 1.15 \\
\hline \multirow[t]{2}{*}{ D5 } & 19 & $\mathbf{M}$ & Myositis ossificans & & & & & \\
\hline & & & progressiva & 10.4 & 13.4 & 23.8 & 17.0 & 0.77 \\
\hline D6 & 20 & $\mathbf{M}$ & Hyperthyroid & 36.1 & 43.1 & 79.2 & 44.0 & 0.84 \\
\hline D7 & 41 & $\mathbf{M}$ & Rheu. arth. & 15.7 & 19.5 & 35.2 & 19.2 & 0.81 \\
\hline D8 & 45 & $\mathbf{M}$ & Rheu. arth. & 25.4 & 25.4 & 50.8 & 29.7 & 1.00 \\
\hline D9 & 69 & $\mathrm{~F}$ & Rheu. arth. & 18.8 & 22.8 & 41.6 & 34.5 & 0.82 \\
\hline D10 & 25 & $\mathbf{M}$ & Systemic lupus & 32.4 & 30.3 & 62.7 & 31.3 & 1.06 \\
\hline D11 & 49 & $\mathrm{~F}$ & Scleroderma & 16.9 & 16.1 & 33.0 & 20.6 & 1.05 \\
\hline D12 & 19 & $\mathrm{~F}$ & Ehlers-Danlos & 24.4 & 20.2 & 44.6 & 27.9 & 1.20 \\
\hline \multirow[t]{2}{*}{ D13 } & 25 & $\mathbf{M}$ & Osteogenesis & & & & & \\
\hline & & & imperfecta & 16.4 & 12.9 & 29.3 & 19.5 & 1.26 \\
\hline D14 & 5 & $\mathrm{~F}$ & Cystic fibrosis & 14.4 & 12.8 & 27.2 & 34.0 & 1.12 \\
\hline D15 & 19 & $\mathrm{~F}$ & Pyknodysostosis & 9.9 & 9.6 & 19.5 & 13.9 & 1.04 \\
\hline D16 & 31 & $\mathrm{~F}$ & Achondroplast & 14.4 & 11.5 & 25.9 & 18.2 & 1.25 \\
\hline D17 & 51 & $\mathbf{M}$ & Achondroplast & 18.1 & 15.9 & 34.0 & 26.0 & 1.14 \\
\hline \multirow[t]{2}{*}{ D18 } & 53 & $\mathbf{M}$ & Pseudoxanthoma & & & & & \\
\hline & & & elasticum & 31.1 & 25.7 & 56.8 & 29.8 & 1.20 \\
\hline D19 & 65 & $\mathbf{M}$ & Burns & 63.8 & 29.2 & 93.0 & 54.8 & 2.18 \\
\hline \multirow[t]{2}{*}{$\mathrm{D} 20$} & 7 & $\mathbf{F}$ & Appendectomy & & & & & \\
\hline & & & wound & 18.0 & 13.0 & 31.0 & 37.5 & 1.37 \\
\hline
\end{tabular}

* Corrected by creatinine (18).

One can see that a collagen-free diet has only a small effect on the levels of excreted hydroxylysyl glycosides in the urine. There is at the most a $15 \%$ decrease from basal levels. On the other hand, ingestion of $24 \mathrm{~g}$ of gelatin increased excretion levels $30 \%$ or so in volunteer A from the basal level. However, this is an exceedingly large amount of gelatin to ingest in 1 day and nothing approaching it would likely be encountered in everyday diets. Thus, it would appear that normal diets have only small effects upon urinary excretion of
OHLG's the major portion of the glycosides excreted being endogenously derived products.

Column chromatography of an alkaline hydrolysate of the commercial gelatin used in the dietary experiments showed that $24 \mathrm{~g}$ of this gelatin contains 86.3 $\mu$ moles of Hyl-Gal-Glc and $43.2 \mu$ moles of Hyl-Gal. From these values it can be calculated that a maximum of $15-20 \%$ of the OHLG's present in the $24 \mathrm{~g}$ of gelatin ingested appeared in the urine. Much of it must have been either completely degraded or not absorbed. 
Effect of age and disease on 24-hr excretion levels of urinary O-hydroxylysyl glycosides. Table III summarizes the results obtained when the levels of urinary Hyl-Gal-Glc and Hyl-Gal were measured in 35 normal and diseased subjects of differing ages and sex. In order to correct for differences in size the sum of the glycosides in $\mu$ moles per square meter of surface area has been expressed for each subject $(21,23)$. Fig. 5 shows the results of plotting the sum of the glycosides for each subject, corrected for differences in size, against age. On the basis of this limited data the OHLG levels among the normals are significantly higher in children. OHLG levels from diseased subjects are included in the same plot and, as a group, appear to be higher than those from normals of the same age.

The right hand scale in Fig. 5 relates the collagen turnover equivalents (CEG) per square meter to $\mu$ molar excretion of OHLG's per square meter given by the left hand scale. An obvious difference between CEG and hydroxyproline collagen turnover equivalents (CEP) is apparent when one plots the mean and the range of CEP per square meter on the right hand scale against age in Fig. 5. These values for CEP were calculated from milligrams of hydroxyproline per square meter vs. age as given by Jasin, Fink, Wise, and Ziff (21). The glycoside collagen equivalents from the 15 normal subjects are consistently two to five times higher than the mean hydroxyproline collagen equivalents of the same age range. These results suggest that urinary OHLG's might more quantitatively reflect collagen turnover than urinary hydroxyproline.

Comparison of hydroxylysyl glycoside and hydroxyproline collagen turnover equivalents. In order to confirm the findings that collagen turnover equivalents

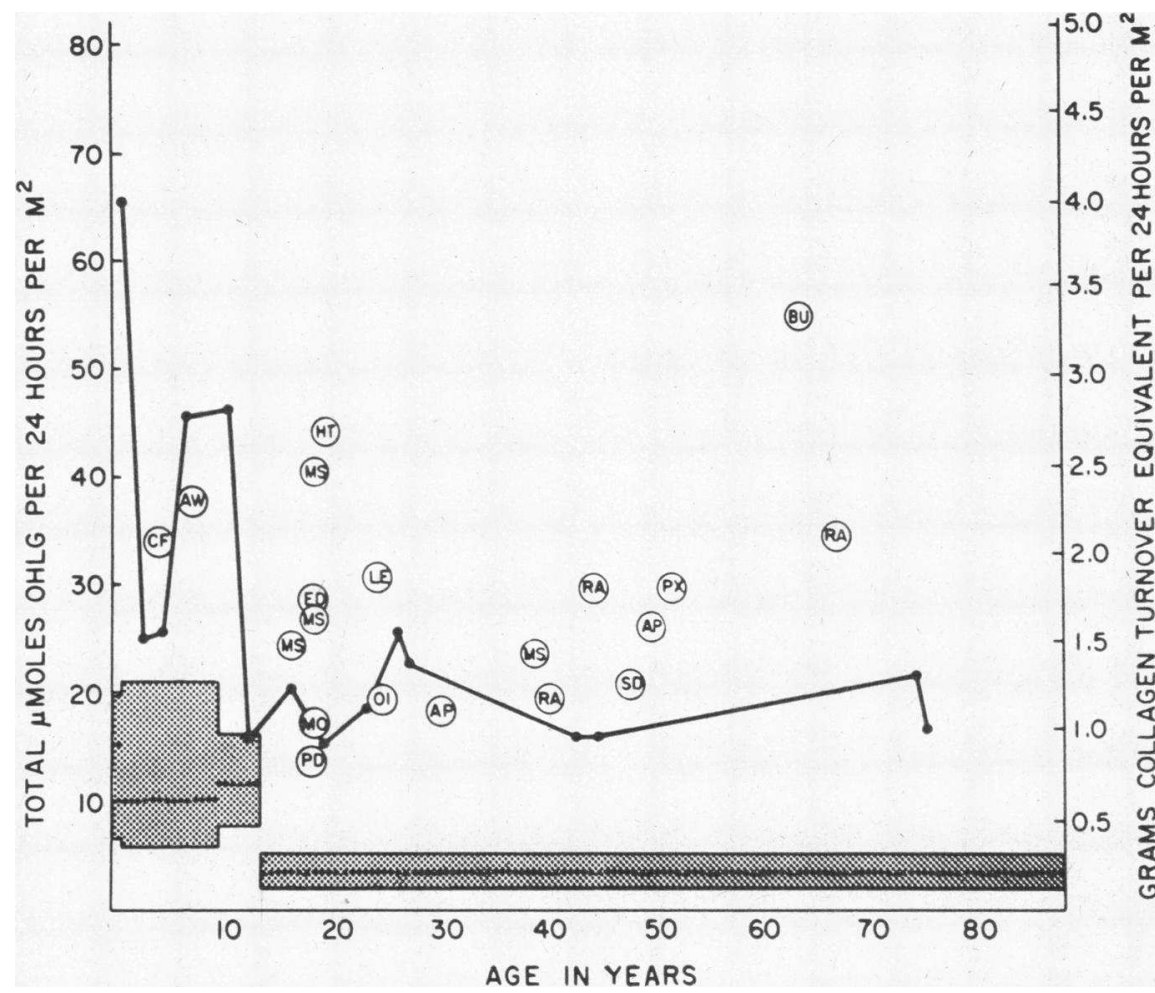

FIGURE $524 \mathrm{hr}$ urinary hydroxylysyl glycoside excretion with age and disease. Total micromoles of OHLG's excreted in $24 \mathrm{hr}$ per square meter of surface area vs. age for 15 normal subjects and 20 patients with varying disorders, the majority of which affect connective tissues in some way. The right hand scale gives excretion in grams collagen turnover equivalents per $24 \mathrm{hr}$ per square meter surface area. ( $-\bullet)$ Normals; the Marfan syndrome (MS) ; Ehlers-Danlos syndrome (ED); osteogenesis imperfecta (OI); pseudoxanthoma elasticum (PX); myositis ossificans progressiva (MO) ; rheumatoid arthritis (RA); systemic lupus erythematosus (LE); systemic scleroderma (SD); hyperthyroidism (HT) ; severe skin burns (BU); pyknodysostosis (PD) ; achondroplastic dwarf (AP) ; cystic fibrosis (CF); and appendectomy wound (AW). For comparison the mean (.....) and the range (shaded areas) of hydroxyproline collagen turnover equivalent excretion vs. age have been included as gram collagen turnover equivalents per $24 \mathrm{hr}$ per square meter surface area (22). 
TABLE IV

Comparison of Urinary O-Hydroxylysyl Glycosides and Hydroxyproline as Indicators of Collagen Metabolism

\begin{tabular}{|c|c|c|c|c|c|c|c|}
\hline \multirow[b]{2}{*}{ No. } & \multirow[b]{2}{*}{ Age } & \multirow[b]{2}{*}{ Urine from } & & \multicolumn{2}{|c|}{$\begin{array}{l}\text { Minimum grams } \\
\text { of collagen } \\
\text { broken down per } \\
24 \mathrm{hr} \text { per }\end{array}$} & \multicolumn{2}{|c|}{$\begin{array}{l}\text { Estimated \% of } \\
\text { total body collagen* } \\
\text { represented by }\end{array}$} \\
\hline & & & & CEP & CEG $\ddagger$ & CEP & CEG \\
\hline \multicolumn{8}{|c|}{$m g H y p / 24 h r$} \\
\hline $\mathrm{N} 2$ & 3 & Normal & 51 & 0.4 & 1.0 & 0.05 & 0.11 \\
\hline N4 & 7 & Normal & 78 & 0.6 & 2.3 & 0.05 & 0.17 \\
\hline N7 & 13 & Normal & 127 & 1.0 & 1.2 & 0.04 & 0.05 \\
\hline N12 & 28 & Normal & 47 & 0.4 & 3.7 & 0.01 & 0.08 \\
\hline N15 & 76 & Normal & 20 & 0.2 & 2.3 & 0.01 & 0.08 \\
\hline D1 & 17 & Marfan & 78 & 0.6 & 2.1 & 0.03 & 0.09 \\
\hline D6 & 20 & Hyperthyroid & 264 & 2.2 & 4.9 & 0.06 & 0.17 \\
\hline D16 & 31 & Achondroplast & 33 & 0.3 & 1.1 & 0.013 & 0.05 \\
\hline D18 & 65 & Burns & 309 & 2.5 & 5.6 & 0.08 & 0.21 \\
\hline
\end{tabular}

* Calculations based upon the fact that in a $65 \mathrm{~kg}$ man there is $11.5 \mathrm{~kg}$ of protein (33), $25 \%$ of which is collagen (34).

‡ Calculated from Table III.

based on total $\mu$ moles of urinary OHLG's (CEG) ex. creted in $24 \mathrm{hr}$ are higher than mean collagen turnover equivalents based on urinary hydroxyproline excretion per $24 \mathrm{hr}$ (CEP) as reported in the literature, hydroxyproline levels were determined in urinary samples from five normal and four diseased subjects for which OHLG levels had been previously measured. In this way the effect of diet as a variable was eliminated. The results are shown in Table IV. The first column gives the excretion of hydroxyproline for each sample in milligrams per $24 \mathrm{hr}$. The normal range of urinary hydroxyproline for adults is $15-60 \mathrm{mg} / 24 \mathrm{hr}$. Children tend to exhibit considerably higher values than adults (21). In the second column, milligrams of hydroxyproline per $24 \mathrm{hr}$ has been expressed as the corresponding CEP. The third column shows the corresponding CEG for each urine sample (calculated from Table III). In every case CEG is higher than CEP with the majority of the CEG's being two to four times larger, similar to the two to fivefold range of Fig. 5. However, the variation is greater than that evident in Fig. 5, there being a one to ten-fold range.

Effects of age and disease on the urinary molar ratio of Hyl-Gal-Glc to Hyl-Gal. The last column in Table III gives the urinary molar ratio of Hyl-Gal-Glc to Hyl$\mathrm{Gal}$ for each subject. In Fig. 6 these ratios are plotted as a histogram. It is obvious that there is a bimodal distribution of ratios with the two populations centered at

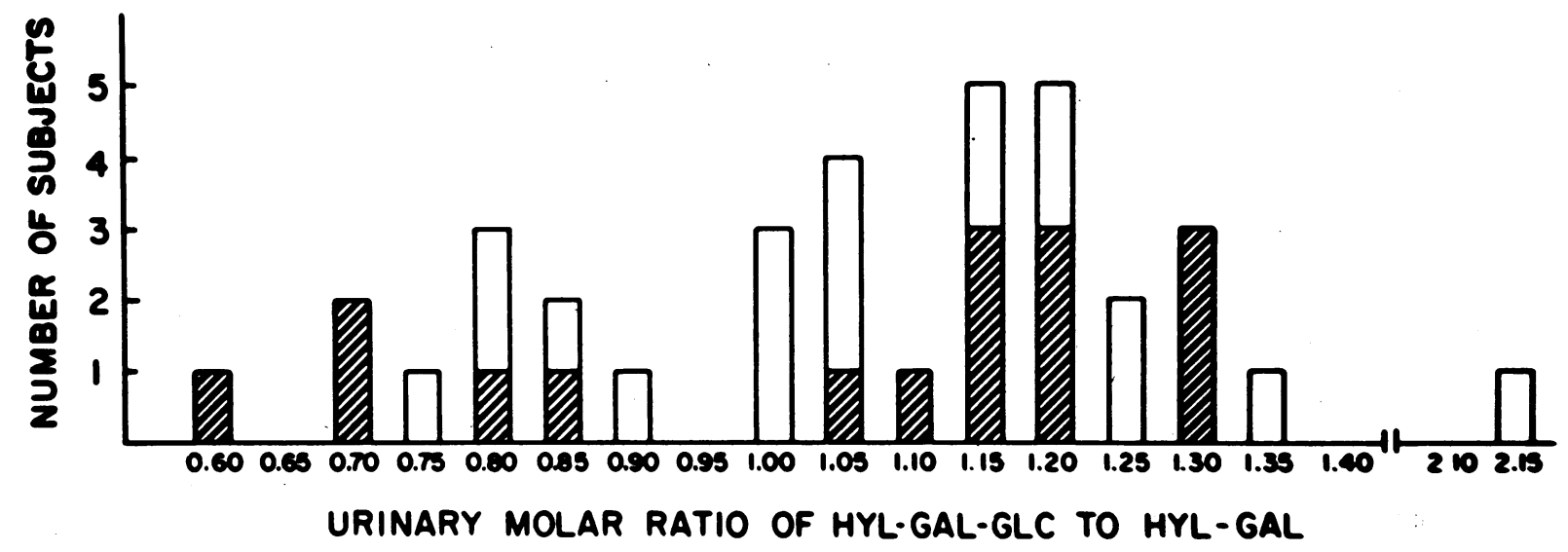

Figure 6 The distribution of urinary molar ratios of Hyl-Gal-Glc to Hyl-Gal in 35 normal and diseased subjects. The black bars represent normals and the white bars abnormals. 
approximately 0.8 and 1.2 and the midpoint at approximately 0.95 .

In Fig. 7 these ratios are plotted against age. It is apparent from this plot that among the normal subjects the ratios tend to be significantly lower in children than in adults. Among the nine adults older than $15 \mathrm{yr}$ of age the ratio is reasonably constant, ranging from 1.07 to 1.31 with a mean of 1.20 . Among the six children less than $15 \mathrm{yr}$ of age the ratio is more variable, ranging from 0.59 to 1.13 with a mean of 0.79 . Only one of these children has a ratio greater than 0.95 . The ratios of the diseased subjects show considerably variation ranging from a low of 0.77 to a high of 2.18. Five of these have ratios less than 0.95 and one has a ratio greater than 1.4.

The molar ratio of Hyl-Gal-Glc to Hyl-Gal among different human connective tissue collagens. The evidence for the existence of at least two distinct populations of ratios of Hyl-Gal-Glc to Hyl-Gal in human urine (Fig. 6 ) prompted further investigations. The molar ratio of Hyl-Gal-Glc to Hyl-Gal in alkaline hydrolysates of soluble guinea pig skin collagen was known to be greater than 2.0 (Fig. 2). Human skin collagen was prepared, an alkaline hydrolysatae examined, and its Hyl-Gal-Glc to Hyl-Gal ratio determined to be 1.61 (Table V). The lower ratios in human urine compared with human skin collagen hydrolysates suggested at least two possibilities. Either there are enzymes in the body that hydrolyze Hyl-Gal-Glc to Hyl-Gal or there is a variable ratio

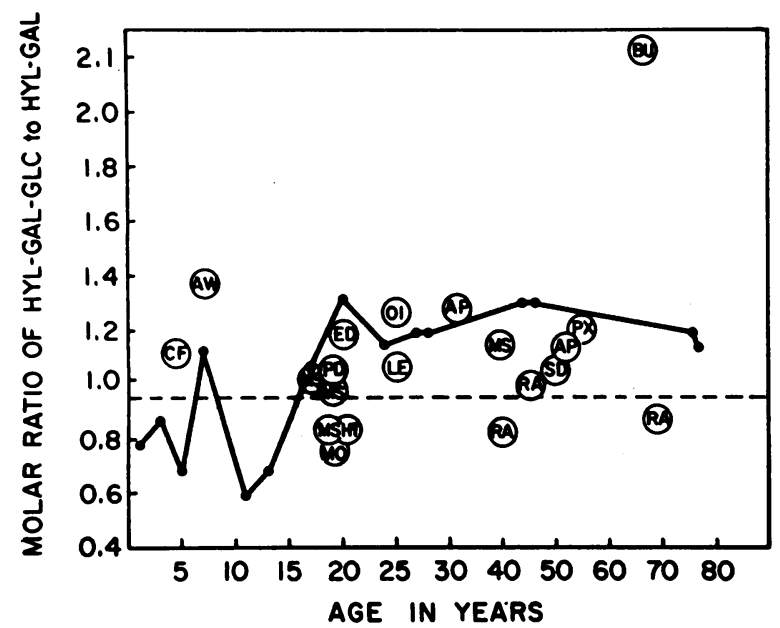

FIGURE 7 The relationship of the urinary molar ratio of Hyl-Gal-Glc/Hyl-Gal to age. (- - ) Normals; the Marfan syndrome (MS); (PX) pseudoxanthoma elasticum; (ED) Eylers-Danlos syndrome; (OI) osteogenesis imperfecta; (MO) myositis ossificans progressiva; (HT) hyperthyroidism; (RA) rheumatoid arthritis; (SD) scleroderma; (LE) systemic lupus erythematosis; (BU) severe skin burns; (AP) achondroplasia; (PD) pyknodysostosis; (CF) cystic fibrosis; (AW) appendectomy wound.
TABLE V

Hyl-Gal-Glc to Hyl-Gal Ratios among Different Human Connective Tissue Collagens

\begin{tabular}{lcccc}
\hline \multirow{2}{*}{$\begin{array}{c}\text { Source of } \\
\text { human } \\
\text { collagen* }\end{array}$} & \multicolumn{2}{c}{ Total mg hexoseł in } & $\begin{array}{c}\text { Hyl-Gal- } \\
\text { Glc/Hyl- } \\
\text { Gal }\end{array}$ & $\begin{array}{c}\% \text { dry } \\
\text { weight as } \\
\text { OHLG } \\
\text { hexose }\end{array}$ \\
\cline { 2 - 5 } Adult skin & 0.174 & 0.054 & 1.61 & 0.22 \\
Adult bone & 0.035 & 0.113 & 0.15 & 0.14 \\
Adult tendon & 0.142 & 0.054 & 1.32 & 0.19 \\
Adult cartilage & 0.674 & 0.280 & 1.20 & 0.97 \\
Infant cartilage & 1.122 & 0.298 & 1.89 & 1.42 \\
\hline
\end{tabular}

* Amino acid analyses of acid hydrolysates of each collagen were similar to other published analyses of human collagen except that the cartilage collagen had measurable levels of cysteine and higher than usual hydroxylysine levels (11 residues $/ 1000$ vs. $4-7$ residues $/ 1000$ for other collagens).

$\ddagger$ In $100 \mathrm{mg}$ of collagen.

of Hyl-Gal-Glc to Hyl-Gal among different collagenous tissues of the body, the urinary ratio depending upon each collagen's proportionate contribution to the metabolic pool.

In order to investigate the latter possibility different insoluble human connective tissue collagens were prepared (from tendon, cartilage, and bone, in addition to skin) and subjected to alkaline hydrolysis in order to free the alkali stable OHLG's for analysis by column chromatography. It was found that the ratios of Hyl-GalGlc to Hyl-Gal in adult insoluble tendon and cartilage and in infant cartilage collagens are comparable to that of adult insoluble skin collagen, being 1.32, 1.20, and 1.89 respectively, while that of adult insoluble bone collagen is markedly different, being 0.15 (Table V). This means that bone collagen hydrolysates contain little of the disaccharide, Hyl-Gal-Glc.

\section{DISCUSSION}

The first detection of the O-hydroxylysyl glycosides (OHLG's) as a class of compounds was in urine (9). Subsequently, similar compounds have been reported in bovine glomerular basement membrane and in other vertebrate collagens by Spiro $(10,11)$, and there is evidence for their presence in invertebrate collagens (24). Glycosylating enzymes involved in the biosynthesis of the OHLG's have been reported by Bosmann and Eylar (25) and Spiro and Spiro (26).

Spiro (10), on the basis of periodate oxidation, methylation, galactose oxidase treatment, and studies with the enzymes $\alpha$ - and $\beta$-gluco- and galactosidases, proposes a structure for Hyl-Gal-Glc of $2-O-\alpha-\mathrm{D}-$ glucopyranosyl- $O-\beta$-D-galactopyranosyl hydroxylysine. Preliminary results from molecular rotation studies on $\mathrm{Hyl}$ $\mathrm{Gal}$ indicate that the configuration in the urinary com- 
pound is also $\beta$, although the proximity of the measured specific rotation to zero precludes an entirely reliable conclusion. ${ }^{1}$

The acetone precipitation procedure utilized in the original isolation of urinary OHLG's, a modification of a method reported by Estes and Golaszewski (12), is derived from procedures designed to precipitate the Tamm-Horsfall mucoprotein from urine $(27,28)$, a high molecular weight protein thought to be secreted by renal tubular cells. Since the two front running hexose peaks shown in Fig. 1 have no measurable levels of hydroxylysine-containing peptides (the trace levels of hydroxylysine in pool II were considered most likely to be overlap from pool III), the breakthrough (peak I) probably represents in part the mucoprotein of TammHorsfall, but the nature of peak II, which separates into several peaks on a Dowex 50 -citrate buffer system, ${ }^{1}$ is unknown.

Several attempts, with negative results, have been made to identify urinary compounds similar in composition to the hexapeptide Gly-Met-Hyl (Gal-Glc)-GlyHis-Arg (17) obtained from proteolytic digests of collagen, indicating that such large collagen fragments most likely are not present in urine under normal conditions. The findings of Estes and Golaszewski (12) of "mucoprotein" fractions from urine of severely burned patients containing proportionately large amounts of hydroxylysine, methionine, histidine, and arginine suggest, however, that under certain highly abnormal conditions, such as severe burns, significant amounts of the hexapeptide may appear in urine.

The higher excretion of total OHLG in children is consistent with the finding that children have a higher collagen metabolism than adults (21), as measured by urinary hydroxyproline excretion. Although these results would certainly become more meaningful if the data included sufficient controls to merit statistical analysis the time required for each analysis precludes the study of the required number of samples. Another potential problem in the interpretation of these data is the fact that urine donors were not on collagen-free diets. This problem seems to be minimal, however, since the dietary studies indicate that diet plays a relatively minor role in the urinary excretion of OHLG's.

The majority of patients with heritable connective tissue and "collagen vascular" disorders have higher 24-hr levels of OHLG's than comparable controls. Extremely high excretion levels were noted in one example (of four) of the Marfan syndrome, a case of hyperthyroidism, and an 8 day old burn involving $50 \%$ of the body surface area. All three abnormalities have been reported to be associated with high urinary hydroxyproline levels $(2,4,29)$.

\footnotetext{
${ }^{1}$ Unpublished data.
}

There are several lines of evidence which indicate that urinary OHLG's are metabolic products of endogenous collagen. (a) Hydroxylysyl glycosides are apparently unique to collagen-like proteins in vertebrates, certainly to the extent that hydroxyproline is unique. (b) The dietary experiments indicate that the greater portion of the urinary OHLG's are endogenously derived. (c) To the extent of the data contained in this communication, the OHLG's parallel collagen metabolism with age and disease as measured by urinary hydroxyproline excretion.

According to one study, that of Woessner in the postpartum rat (8), less than $15 \%$ of the hydroxyproline of degraded collagen appears in the urine. A high renal threshold for the excretion of free hydroxyproline (30) as well as enzymatic degradation of this hydroxyproline (31) account for its low yield in urine. Over $95 \%$ of the hydroxyproline present in urine is in a peptidebound form (32).

More recent work than that of Woessner's suggests a higher yield of hydroxyproline. According to Weiss and Klein $25 \%$ of the hydroxyproline of degraded collagen is excreted in the urine (31). If one accepts this value, urinary OHLG's account for from 50 to $100 \%$ of degraded collagen (CEG's being two to four times CEP's). One way to explain these results is to assume that collagen derived OHLG's are partially to completely protected from enzymatic degradation, as are prolylhydroxyprolyl peptides (31).

Thus, urinary OHLG's seem to more closely reflect collagen turnover in a quantitative manner than urinary hydroxyproline. Admittedly, the factor 0.0045 used in calculating CEG's is rather variable, the per cent content of OHLG's being considerably higher in certain collagens such as basement membrane (10). However, since the major mass of body collagen (bone, skin, and tendon) all have similar OHLG per cent content (Table V), this possible difficulty would appear minimized.

The results of Table V suggest a possible explanation for the existence of two populations of OHLG ratios in human urines. The individuals with a low mean ratio may have a proportionate increase in the degradative products of bone collagen in their urine because of an increased rate of bone metabolism. This interpretation is supported when one compares the composition of the two populations. All the urines from normal individuals belonging to the population with low ratios (a Hyl-GalGlc to Hyl-Gal ratio of less than 0.95) are children with active epiphyseal growth and an increased bone turnover relative to adults. All normal adults fall into the high ratio population.

Of the five abnormal urines which belong to the low ratio population one can argue that four represent $a b$ - 
normalities in bone metabolism. Two of these are active cases of rheumatoid arthritis. The one case of inactive rheumatoid arthritis included in the series falls into the high ratio population. One of the abnormal urines is from a case of the Marfan syndrome, a heritable disease with marked long bone overgrowth and other skeletal abnormalities (29). Another abnormal urine is from a case of myositis ossificans progressiva, a disorder in which there is abnormal bone formation through ossification of normally uncalcified connective tissue (29). The fifth example is a case of hyperthyroidism which, though not clearly related to bone metabolism, does represent an example of generalized hypermetabolism.

Among the abnormal urines in the high ratio population, the single highest ratio belongs to a severely burned individual in whom it is logical to assume an increase in turnover of skin collagen compared with other collagens, including bone.

A second possible explanation for the two populations of OHLG ratios observed in human urines is that children and certain examples of hypermetabolism (e.g., hyperthyroidism) have an increased activity of a hypothetical catabolic enzyme which produces increased urinary Hyl-Gal as a breakdown product of Hyl-GalGlc. However, we feel this to be a less likely explanation for the following reasons: $(a)$ no such enzyme has as yet been reported; $(b) \mathrm{Hyl}-\mathrm{Gal}$ is not necessarily a catabolic product of Hyl-Gal-Glc as it occurs in collagen hydrolysates under conditions in which Hyl-Gal-Glc is stable; and (c) variations in bone collagen turnover do exist and can explain the data thus far.

A study of the ratios of Hyl-Gal-Glc to Hyl-Gal in urine from disorders involving a definite increase in bone collagen turnover, such as extensive fractures, Paget's disease, metastatic carcinoma, and rickets, should provide an additional test for the hypothesis that variation in bone collagen turnover is the basis for two populations of urinary OHLG ratios.

\section{ACKNOWLEDGMENTS}

Grateful appreciation is expressed to Patsy Seta for her assistance in performing analyses of hydroxylysyl glycosides and to Mr. John Ford for his technical assistance and advice. We are especially indebted to Dr. Victor McKusick of the Johns Hopkins Hospital Department of Medicine and his postgraduate fellow, Dr. Bryan Walker, for providing us with urine samples from patients with heritable connective tissue disorders; and to Mr. Roy Meals for his help in the preparation of urinary glycosides.

This investigation was supported by Grant No. GB12940 of the National Science Foundation and by Grant No. AM11821 of the National Institute of Arthritic and Metabolic Diseases.

\section{REFERENCES}

1. Prockop, D. J., and K. I. Kivirikko. 1968. Hydroxyproline and the metabolism of collagen. In Treatise on Collagen. B. S. Gould, editor. Academic Press, New York. 2A : 215

2. Kivirikko, K. I., M. Koivusalo, O. Laitinen, and B. A. Lamberg. 1964. Hydroxyproline in the serum and urine of patients with hyperthyroidism. J. Clin. Endocrinol. Metab. 24: 222.

3. Benoit, F. L., G. B. Theil, and R. H. Watten. 1963. Hydroxyproline excretion in endocrine disease. Metab. (Clin. Med.). 12: 1072.

4. Klein, L., P. H. Curtiss, Jr., and J. H. Davis. 1962. Collagen breakdown in thermal burns. Surg. Forum. 13: 459.

5. Klein, L., and P. H. Curtiss, Jr. 1963. The effect of vitamin $\mathrm{D}$ on urinary hydroxyproline in vitamin D-deficiency ricketts and resistant rickets. J. Bone Joint Surg. A Amer. Vol. 45: 1542.

6. Platt, W. D., L. H. Doolittle, and J. W. S. Hartshorn. 1964. Urinary hydroxyproline excretion in metastatic cancer of bone. N. Engl. J. Med. 271: 287.

7. Crabbe, P., and K. J. Isselbacher. 1965. Urinary hydroxyproline excretion in malabsorption states. Gastroenterology. 48: 307.

8. Woessner, J. F., Jr. 1962. Catabolism of collagen and noncollagen protein in the rat uterus during post-partum involution. Biochem. J. 83: 304 .

9. Cunningham, L. W., J. D. Ford, and J. P. Segrest. 1967. The isolation of identical hydroxylysyl glycosides from hydrolysates of soluble collagen and from human urine. J. Biol. Chem. 242: 2570.

10. Spiro, R. G. 1967. The structure of the disaccharide unit of the renal glomerular basement membrane. J. Biol. Chem. 242: 4813.

11. Spiro, R. G. 1969. Characterization and quantitative determination of the hydroxylysine-linked carbohydrate units of several collagens. J. Biol. Chem. 244: 602 .

12. Estes, F. L., and T. Golaszewski. 1965. Isolation and characterization of a mucoprotein fraction from urine. Fed. Proc. 24: 606. (Abstr.)

13. Moore, S., and W. H. Stein. 1963. Chromatographic determination of amino acids by the use of automatic recording equipment. In Methods in Enzymology. S. P. Colowick and N. O. Kaplan, editors. Academic Press, New York. 6: 819.

14. Judd, J., W. Clouse, J. Ford, J. van Eys, and L. W. Cunningham. 1962. An automatic determination of protein-bound hexose. Anal. Biochem. 4: 512.

15. Spackman, D. H., W. H. Stein, and S. Moore. 1958. Automatic recording apparatus for use in the chromatography of amino acids. Anal. Chem. 30: 1190.

16. Partridge, S. M. 1949. Aniline hydrogen phthalate as a spraying reagent for chromatography of sugars. $\mathrm{Na}$ ture (London). 164: 443.

17. Butler, W. T., and L. W. Cunningham. 1966. Evidence for the linkage of a disaccharide to hydroxylysine in tropocollagen. J. Biol. Chem. 241: 3882.

18. Stearns, G., K. J. Newman, J. B. McKinley, and P. C. Jeans. 1958. The protein requirements of children from one to ten years of age. Ann. N. Y. Acad. Sci. 69: 857.

19. Prockop, D. J., and A. Sjoerdsma. 1961. Significance of urinary hydroxyproline in man. J. Clin. Invest. 40: 843. 
20. Cunningham, L. W., and J. D. Ford. 1968. A comparison of glycopeptides derived from soluble and insoluble collagens. J. Biol. Chem. 243: 2390.

21. Jasin, H. E., C. W. Fink, W. Wise, and M. Ziff. 1962. Relationship between urinary hydroxyproline and growth. J. Clin. Invest. 41: 1928.

22. Prockop, D. J., and S. Udenfriend. 1960. A specific method for the analysis of hydroxyproline in tissues and urine. Anal. Biochem. 1: 228.

23. Nelson, W. E. 1964. Textbook of Pediatrics. W. B. Saunders, Philadelphia. 8th edition. 210.

24. Jeanloz, R. W., A. K. Bhattacharyya, and G. P. Roberts. 1969. The Carbohydratae Components of Collagen. Hoppe-Seyler's Z. Physiol. Chem. 350: 663.

25. Bosmann, H. B., and E. H. Eylar. 1968. Attachment of carbohydrate to collagen. Isolation, purification and properties of the glucosyl transferase. Biochem. Biophys. Res. Commun. 30: 89.

26. Spiro, R. G., and M. J. Spiro. 1968. Enzymatic synthesis of the hydroxylysine-linked disaccharide of basement membranes and collagens. Fed. Proc. 27: 345

27. Anderson, A. J., and N. F. MacLagan. 1955. The isolation and estimation of urinary mucoproteins. Biochem. J. 59: 638 .
28. Maxfield, M., and D. Stefanye. 1962. The amino acid composition of normal human urinary mucoprotein. $J$. Biol. Chem. 237: 2522.

29. McKusick, V. A. 1966. Heritable Disorders of Connective Tissue. The C. V. Mosby, Co., St. Louis.

30. Prockop, D. J., H. R. Keiser, and A. Sjoerdsma. 1962. Gastrointestinal absorption and renal excretion of hydroxyproline peptides. Lancet. ii: 527.

31. Weiss, P. H., and L. Klein. 1969. The quantitative relationship of urinary peptide hydroxyproline excretion to collagen degradation. J. Clin. Invest. 48: 1.

32. Ziff, M., A. Kibrick, E. Dresner, and H. J. Gribetz. 1956. Excretion of hydroxyproline in patients with rheumatic and nonrheumatic diseases. J. Clin. Invest. 35: 579.

33. Davidson, S., A. P. Meiklejohn, and A. Passmore. 1959. Human Nutrition and Dietetics. The Williams \& Wilkins Co., Baltimore. 3.

34. Neuberger, A., and F. F. Richards. 1964. Protein biosynthesis in mammalian tissues. II. Studies on turnover in the whole animal. In Mammalian Protein Metabolism. H. N. Munro and J. B. Allison, editors. Academic Press, New York. 1: 243. 